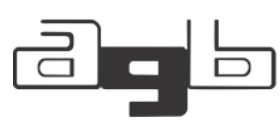

\title{
DESIGUALDADE SOCIOESPACIAL E PANDEMIA: CONSIDERAÇÕES ACERCA DA DISSEMINAÇÃO DA COVID-19 EM POÇOS DE CALDAS (MG)
}

\author{
Eduardo de Araujo da Silva ${ }^{1}$
}

RESUMO: Os grupos sociais excluídos e segregados sofrem com diversos problemas socioespaciais, como, por exemplo, a falta de moradia digna, dificuldade de acesso aos serviços públicos e privados, carência de serviços urbanos básicos, às vezes problemas relacionados a desastres ambientais e contaminação por doenças. No cenário pandêmico a situação dessa parcela da população se agrava. Estudiosos indicam que os impactos causados pela pandemia COVID-19 mostraram-se distintos entre os diferentes grupos sociais e lugares, visto que as populações de baixa renda e suas regiões foram severamente afetadas pelo novo coronavírus. Visando contribuir com a temática, este artigo faz aproximações entre a desigualdade socioespacial e a propagação diferenciada da COVID-19 no espaço geográfico. Para tanto, foi selecionado o município de Poços de Caldas (MG) como área de estudo. Observa-se que as regiões urbanas com maiores contingentes populacionais, maiores médias de moradores por domicílio, maiores percentuais de população autodeclarada parda e negra, e menores rendas médias dos moradores apresentaram os maiores números de casos confirmados de COVID-19.

PALAVRAS-CHAVE: Segregação socioespacial; Novo Coronavírus; Espaço intraurbano; Regiões urbanas; Cidade média.

\section{SOCIO-SPACE INEQUALITY AND PANDEMIC: CONSIDERATIONS ABOUT THE DISSEMINATION OF COVID-19 IN POÇOS DE CALDAS} (MG)

\begin{abstract}
Excluded and segregated social groups suffer from various socio-spatial problems, such as lack of decent housing, difficulty in accessing public and private services, lack of basic urban services, sometimes problems related to environmental disasters and contamination by diseases. In the pandemic scenario, the situation of this portion of the population worsens. Scholars indicate that the impacts caused by the COVID-19 pandemic proved to be distinct between different social groups and places, as low-income populations and their regions were severely affected by the new coronavirus. Aiming to contribute to the theme, this article brings together socio-spatial inequality and
\end{abstract}

\footnotetext{
${ }^{1}$ Mestre em Geografia pelo Programa de Pós-Graduação em Geografia da Universidade Federal de Alfenas - PPGEO - UNIFAL-MG. E-mail: eduardosilva.geografia@gmail.com
} 
the differentiated spread of COVID-19 in geographic space. Therefore, the municipality of Poços de Caldas (MG) was selected as the study area. It is observed that urban regions with higher population groups, higher averages of residents per household, higher percentages of self-declared mixed race and black populations, and lower average incomes of residents had the highest numbers of confirmed cases of COVID-19.

KEYWORDS: Socio-spatial segregation; New Coronavirus; Intra-urban space; Urban regions; Medium-sized city.

\section{DESIGUALDAD SOCIOESPACIAL Y PANDEMIA: CONSIDERACIONES SOBRE LA DIFUSIÓN DEL COVID-19 EN POÇOS DE CALDAS (MG)}

RESUMEN: Los grupos sociales excluidos y segregados padecen diversos problemas socioespaciales, como falta de vivienda digna, dificultad para acceder a servicios públicos y privados, falta de servicios urbanos básicos, a veces problemas relacionados con desastres ambientales y contaminación por enfermedades. En el escenario de una pandemia, la situación de esta porción de la población empeora. Los académicos indican que los impactos causados por la pandemia de COVID-19 demostraron ser distintos entre diferentes grupos sociales y lugares, ya que las poblaciones de bajos ingresos y sus regiones se vieron gravemente afectadas por el nuevo coronavirus. Con el objetivo de contribuir a la temática, este artículo reúne la desigualdad socioespacial y la propagación diferenciada de COVID-19 en el espacio geográfico. Por lo tanto, se seleccionó el municipio de Poços de Caldas (MG) como área de estudio. Se observa que las regiones urbanas con mayores grupos poblacionales, mayores promedios de residentes por hogar, mayores porcentajes de población autodeclarada mestiza y negra, y menores ingresos promedio de residentes tuvieron el mayor número de casos confirmados de COVID-19.

PALABRAS CLAVE: Segregación socioespacial; Nuevo coronavirus; Espacio intraurbano; Regiones urbanas; Ciudad media.

INTRODUÇÃO

Relatado em dezembro de 2019, o novo coronavírus SARS-CoV-2 (vírus causador da doença COVID-19) teve como epicentro a cidade de Wuhan, Hubei, na República Popular da China e se espalhou rapidamente para todos os continentes. No dia 30 de janeiro de 2020, a Organização Mundial da Saúde (OMS), tendo em vista a crescente quantidade de casos confirmados em diversos países, 
declarou o surto como uma emergência de saúde global (VELAVAN e MEYER, 2020).

Diante do cenário pandêmico, diversas pesquisas estão sendo elaboradas para compreender a dinâmica e os impactos da pandemia COVID-19 sobre o mundo. Com efeito, vírus não escolhe hospedeiro por aspectos socioespaciais, entretanto, é observado que os aspectos sociais (renda, educação/instrução, etnia/raça, cultura, idade, gênero, ocupação e contextos políticos) e espaciais (contingente populacional, concentração de pessoas, densidade demográfica, diferenciação espacial e segregação socioespacial) influenciam na propagação de epidemias e no impacto dessas sobre os diferentes grupos sociais.

Tendo isso em vista, este artigo tem o objetivo de fazer aproximações entre as desigualdades socioespaciais e a disseminação da COVID-19 sobre o espaço geográfico, assim como apresentar resultados empíricos tendo como área de estudo o município de Poços de Caldas (MG). Alertamos não haver pretensão de esgotar o tema, já que o evento estudado ainda está em processo e que novos estudos poderão ser realizados acerca da pandemia.

O trabalho está dividido em duas partes: a primeira traz como discussão os impactos da pandemia da COVID-19 relacionando as desigualdades socioespaciais; a segunda traz considerações acerca da disseminação da COVID19, tendo como área de estudo o município de Poços de Caldas (MG).

\section{METODOLOGIA}

Foram coletados e analisados trabalhos acadêmicos que abordassem o tema desigualdade socioespacial na pandemia da COVID-19. Para compreender a área de estudo selecionada, foram coletados e analisados dados secundários da cidade no site do Instituto Brasileiro de Geografia e Estatística - IBGE, em trabalhos acadêmicos e documentos oficiais elaborados pelo poder público local. 
Os dados referentes à COVID-19 foram coletados do "Painel Coronavírus Poços de Caldas", que está disposto no site da Prefeitura Municipal de Poços de Caldas.

\section{DESIGUALDADE SOCIOESPACIAL E A PANDEMIA COVID-19}

De acordo com Harvey (2020), no cenário pandêmico atual a situação econômica se encontrou vulnerável em todas as partes do mundo. Os setores industriais foram diretamente prejudicados devido às limitações nos serviços de importação/exportação de matéria-prima e produtos (o que prejudicou a produção e o tempo de rotação do capital). O setor de turismo e os sistemas de transporte aéreos ficaram prejudicados pela redução do fluxo das pessoas nesses tempos. Houve o desemprego em massa nas redes hoteleiras, bares e restaurantes, os prestadores de serviços de transporte particular, que, na maioria das vezes, não tem nenhum apoio das empresas vinculadas, estão com demandas reduzidas de trabalho. Eventos de todos os tipos foram cancelados.

Diante dos impactos econômicos ocorridos, outro ponto a ressaltar é a precarização das condições de trabalho pelas políticas neoliberais em processo global. Em entrevista, Achille Mbembe (2020, n.p.) afirma que “o sistema capitalista é baseado na distribuição desigual da oportunidade de viver e de morrer", e que “[...] essa lógica está no coração do neoliberalismo, que deveríamos chamar de necroliberalismo. Esse sistema sempre operou com a ideia de que alguém vale mais do que outros. Quem não tem valor pode ser descartado".

No Brasil, as políticas neoliberais que já estavam em processo (reforma trabalhista, reforma da previdência, supressão das políticas sociais, dentre outras) somaram-se aos impactos socioeconômicos causados pela pandemia. Desse modo, os trabalhadores de menor poder aquisitivo, impossibilitados de realizar um isolamento social efetivo, foram aqueles que deram continuidade à reprodução ampliada do capital (VOLOCHKO, 2020). 
Volochko (2020, p. 39) aponta para uma "necrodemografia do capital", sendo esta

[...] a demografia da morte a orientar as políticas do nosso Estado atualmente, significando o sacrifício necessário de vidas de trabalhadores pobres para que o capital saia vivo da enorme crise provocada pelo isolamento social e pela paralisação geral de diversos setores produtivos durante a pandemia.

Isto é, a parcela pobre da sociedade tornou-se grande alvo da COVID-19, pois os trabalhadores de menor poder aquisitivo, que geralmente moram nas periferias urbanas, dependem diretamente de suas mínimas rendas e de deslocamentos diários por transportes coletivos, dessa maneira, se expõem constantemente ao risco de contaminação.

Nesta conjuntura, Mbembe (2020) afirma que o isolamento social concede ao indivíduo um relativo poder sobre a morte, já que "podemos escapar da morte ou adiá-la" (n.p.). Ou seja, para aqueles que não podem fazer o isolamento social efetivo, como os trabalhadores pobres (formais ou informais), não há nem mesmo o poder de escolha sobre a vida.

Concordamos com Harvey (2020, p. 21) ao afirmar que “[...] o progresso da COVID-19 exibe todas as características de uma pandemia de classe, gênero e raça", pois, se a atual pandemia se dissemina pelo mundo e chega potencialmente a todos, não se pode dizer que ela contamina a todos de modo igual. Os impactos da pandemia se diferenciam sobre os diferentes grupos sociais e, consequentemente, sobre os diferentes lugares.

Ademais, não é novidade ver a ocorrência de problemas socioambientais em setores urbanos mais vulneráveis socialmente. Na mídia é recorrente aparecer grupos sociais de baixa renda vítimas de desastres ambientais, como, por exemplo, desabamentos de encostas ou inundações, e que em suas áreas apresentam significativas incidências de doenças infectocontagiosas devido à 
falta de infraestruturas urbanas e de saneamento básico. Com a pandemia da COVID-19 não foi diferente. Estudos evidenciaram uma crescente relação entre maiores incidências de casos e/ou mortes de COVID-19 e áreas urbanas ocupadas pelas classes sociais de baixo poder aquisitivo.

A partir de diversos estudos empíricos (BARBOSA e TEIXEIRA, 2020; GEPLAN-IFSULDEMINAS, 2020; MATSUMOTO et al., 2020; MARTINUCI et al., 2020; OLIVEIRA, 2020; RIZZATTI et al., 2020), evidenciam-se pontos em comum. As áreas urbanas ocupadas pela população de baixa renda são consideravelmente impactadas pela COVID-19, pelo fato de possuírem grandes contingentes populacionais e elevada densidade demográfica; geralmente, o saneamento básico e de serviços urbanos gerais são precários nessas áreas. Também há de se considerar o que já foi mencionado: uma vez que os trabalhadores pobres não têm a escolha de realizar um isolamento social efetivo, estes podem se contaminar no percurso ao trabalho ou no ambiente de trabalho, assim levando o vírus para seus lares. Portanto, a desigualdade socioespacial se relaciona com a propagação diferenciada do vírus entre os grupos sociais e lugares.

Barbosa e Teixeira (2020) apresentam a relação das taxas de letalidade pela COVID-19 entre as zonas da cidade do Rio de Janeiro. Em suas análises, os autores indicam que, em maior ou menor grau, as taxas de letalidade acompanharam as condições socioeconômicas, dessa maneira, evidenciam uma relação entre as mortes e as desigualdades urbanas. Na Zona Sul e no Centro, apresentaram taxas de letalidade de COVID-19 com 8\% e 7,5\%, respectivamente. Em contrapartida, a Zona Norte e a Zona Oeste da cidade apresentaram taxas de 19\% e 20,5\%. Além disso, os autores apontam para a necessidade de considerar uma possível subnotificação de casos por falta de testagens.

Por seu turno, Oliveira (2020) observa os impactos da COVID-19 relacionada à desigualdade socioespacial de São Paulo. De acordo com o pesquisador, as periferias da Zona Leste da metrópole, as que apresentam maior percentual de 
população parda e negra, apresentaram elevados números de mortos pela COVID-19. As desigualdades étnico-raciais da capital paulista, segundo Oliveira (2020), é resultado da "tríplice segregação socioespacial, étnico-racial e urbana, que produziram espaços segregados por classe, raça e território na cidade" (n.p.). Para o autor, a população trabalhadora de baixa renda, negra e das periferias sofreu maiores impactos da COVID-19.

\section{DESIGUALDADE SOCIOESPACIAL DE POÇOS DE CALDAS E A COVID-19}

Poços de Caldas é o município mais populoso da mesorregião Sul/Sudoeste de Minas, no estado de Minas Gerais. Estima-se que sua população seja de 169,8 mil habitantes em 2021 (IBGE, 2021), sendo esta majoritariamente urbana².

Poços de Caldas apresenta elevados índices socioeconômicos, como o IDHM pontuado em 0,779, além de dispor de um sistema de saneamento consideravelmente completo atualmente (IBGE, 2021). Entretanto, o município, sobretudo, a cidade, apresenta considerável desigualdade socioespacial, que se expressa em uma notável diferenciação socioespacial e na segregação socioespacial local.

A desigualdade socioespacial local foi se constituindo a partir da atuação dos diferentes agentes sociais e econômicos, em diferentes períodos históricos. Ela se expressa na forma urbana atual, em que o centro principal e os setores urbanos ocupados pelas classes sociais de média-alta e alta renda apresentam uma maior facilidade de acesso à oferta de comércios, serviços e espaços de lazer. Por outro lado, os setores urbanos mais distantes e descontínuos do centro principal (e do próprio contexto urbano), que apresentaram menores índices

\footnotetext{
${ }^{2}$ Em 2010, a população total do município apresentava 152.435 pessoas, sendo 148.722 residentes na zona urbana $(97,6 \%)$ e 3.713 residentes na zona rural $(2,4 \%)$.
} 
socioeconômicos, não apresentam as mesmas vantagens locacionais e são mais afetados pelo processo de segregação (SILVA, 2021).

No que tange às medidas de prevenção e enfrentamento da COVID-19 decretadas pelo poder público local, a primeira criada foi o decreto $N^{\circ} 13.279$, do dia 18 de março de 2020. No mesmo havia a suspensão das aulas da Rede Municipal de Ensino; fechamento, por prazo indeterminado, dos espaços públicos de lazer; suspensão de todos os eventos públicos; proibição de refeições no Restaurante Popular; suspensão do funcionamento dos centros de serviços sociais; suspensão das atividades de capacitação que impliquem em aglomeração acima de 10 pessoas e; suspensão de viagens oficiais dos servidores públicos com destino aos locais com contaminação de COVID-19 (PREFEITURA MUNICIPAL DE POÇOS DE CALDAS, 2020). Dois dias após o decreto, no dia 20 de março de 2020, foi registrado o primeiro caso confirmado de COVID-19 em Poços de Caldas.

Após uma série de outros decretos municipais, que, por vezes, flexibilizaram as medidas de contenção e enfrentamento da pandemia, por outras, criaram medidas para prevenção, observou-se o progressivo crescimento no número de casos confirmados e óbitos pela doença. Até o dia 8 de outubro

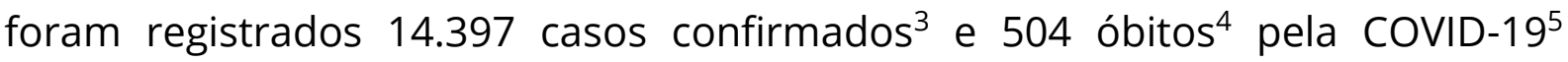
(PREFEITURA MUNICIPAL DE POÇOS DE CALDAS, 2021).

No que se refere aos dados de COVID-19 locais, estes foram divulgados no “Painel Coronavírus Poços de Caldas" no site da Prefeitura Municipal de Poços de Caldas, que apresenta os casos confirmados relacionando alguns aspectos sociais, como gênero e faixa etária, e aspectos espaciais, como a informação da região em que se encontra o caso confirmado da doença (Figura 1).

\footnotetext{
${ }^{3}$ Considerando os casos ativos e já recuperados.

${ }^{4} 218$ óbitos residentes e 286 óbitos não residentes (PREFEITURA MUNICIPAL DE POÇOS DE CALDAS, 2021).

${ }^{5}$ Observou-se o número de casos confirmados e óbitos pela COVID-19 de Poços de Caldas entre os dias 20 de março de 2020 a 8 de outubro de 2021. Estes dados estão disponíveis no Painel Coronavírus Poços de Caldas (PREFEITURA MUNICIPAL DE POÇOS DE CALDAS, 2021).
} 
Observa-se que, até o dia 8 de outubro de 2021, houve notável diferenciação do número absoluto de casos entre as regiões urbanas de Poços de Caldas. A região Leste apresentou o maior número de casos registrados, sendo de 5.327 (37\%). Em seguida, os maiores percentuais de casos confirmados foram: região Sul com 2.768 (19,23\%); região Oeste com 2.379 (16,52\%); Centro com 2.321 (16,12\%); região Centro-Sul com 1.347 (9,36\%), respectivamente. Por sua vez, a região Centro-Leste apresentou somente 12 casos (0,08\%). No que diz respeito aos casos na Zona Rural, foram confirmados 212 casos $(1,47 \%)$ e casos sem informação geográfica foram 31 casos (0,22\%).

Figura 1- Painel Coronavírus Poços de Caldas: Total de casos por região (08/10/2021). Legenda: Leste: 5.327 (37\%). Sul: 2.768 (19,23\%). Oeste: 2.379 (16,52\%). Centro: 2.321 (16,12\%). Centro-Sul: 1.347 (9,36\%). Centro-Leste: 12 (0,08\%). Rural: 212 (1,47\%) Sem Informação (geográfica): 31 (0,22\%).

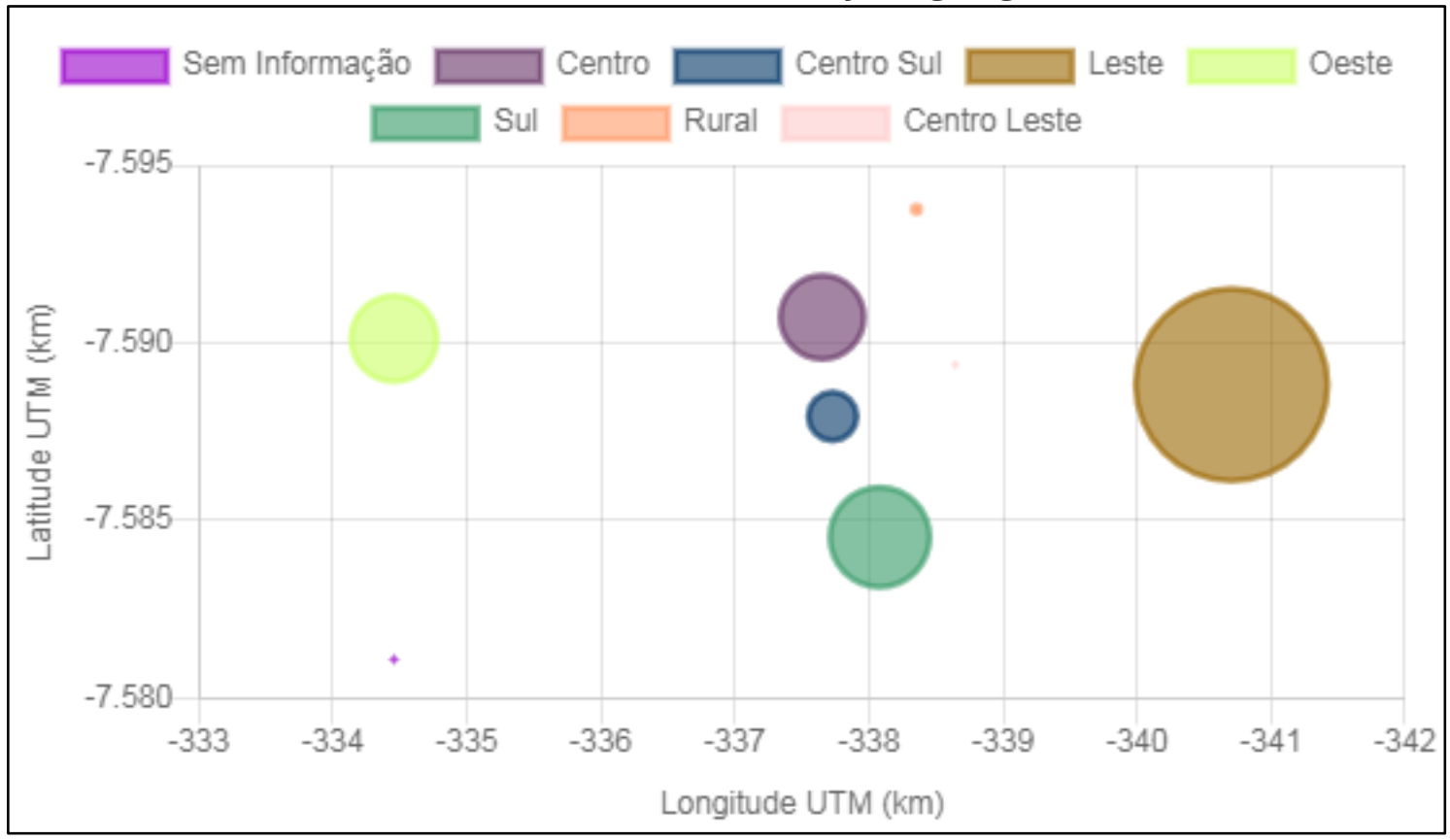

Fonte: Prefeitura Municipal de Poços de Caldas (2021).

Atualmente, as regiões Sul e Leste são as mais populosas da cidade, e, se somadas, representam $47,71 \%$ da população total do município. Isso se relaciona com os expressivos números de casos confirmados nessas regiões. Cabe ressaltar 
que ambas apresentam baixos índices socioeconômicos em seus setores, se comparado às demais regiões urbanas. Os baixos índices socioeconômicos se relacionam com os processos de segregação socioespacial da cidade.

A ocupação urbana em direção leste começou desde os anos 1940, contudo, a partir da década de 1970, a região começou a ser expressivamente loteada, em áreas mais distantes e descontínuas do contexto urbano. A região Sul começou a ser ocupada a partir dos anos finais da década de 1960. Em 1981, foi inaugurado o maior empreendimento de habitação de interesse social no município, o Conjunto Habitacional Dr. Pedro Affonso Junqueira - COHAB, onde foram entregues 1551 casas para a população de baixa renda. Observa-se que este conjunto habitacional foi implantado numa área que antes não havia centralidade, a cerca de 10 quilômetros de distância do centro principal da cidade (SILVA, 2021).

Figura 2 - População total residente, por região urbana

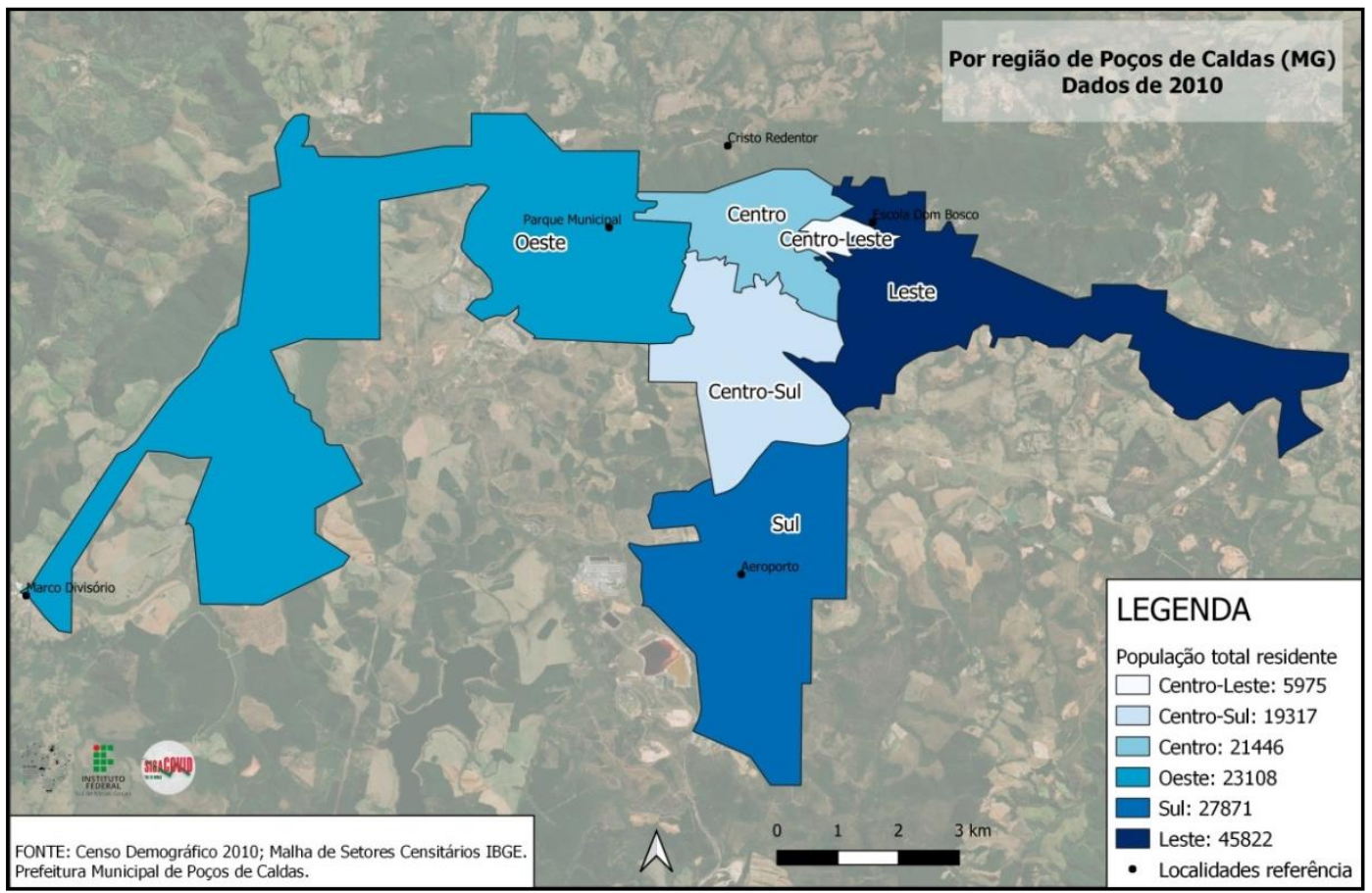

Fonte: GEPLAN-IFSULDEMINAS (2020). 
O Centro, que abriga um expressivo contingente populacional, é composto por uma elevada oferta de comércios e serviços, pontos turísticos, além das moradias. Por ser uma região que é mais voltada às atividades do setor terciário, o valor dos terrenos centrais são expressivamente mais altos do que os de outras regiões, fato esse que contribui para uma expansão verticalizada.

Por sua vez, a região Oeste é composta por conteúdos sociais variados. Nessa região, há loteamentos dos programas de habitação de interesse social (Projeto União I, Projeto União II e Maria Imaculada), bairros de classe média, bairros das classes de alta renda e espaços residenciais fechados de médio e alto padrão. Nela estão dispostos variados espaços públicos e privados que condicionam melhores formas de vida, como: o Parque Municipal, instituições de ensino (todos os níveis), pontos turísticos e uma crescente oferta de empregos, comércio e serviços (SILVA, 2021).

A região Centro-Sul corresponde aos bairros implantados entre as décadas de 1940 e 1960 que tiveram valorização, devido à localização relativamente central e aos bairros que foram implantados após os anos 1970. Os bairros implantados após a década de 1970 apresentam índices socioeconômicos relativamente baixos (SILVA, 2021).

A região Centro-Leste corresponde aos primeiros loteamentos implantados em direção leste, em um dos principais eixos de mobilidade para a cidade. Por ser uma região contínua ao centro principal, sua função além de habitacional, também é comercial (SILVA, 2021). Proporcionalmente, o menor número de infectados foi nessa região, que abriga o menor contingente populacional.

Observa-se que, as maiores médias de moradores por domicílio se encontram nos bairros das regiões Sul e Leste, respectivamente (Figura 3). Isso se relaciona com o que foi apresentado acima, em que, essas regiões foram compostas por habitações populares, que contribuíram para o adensamento populacional de ambas. 
Figura 3 - Média de moradores por domicílio

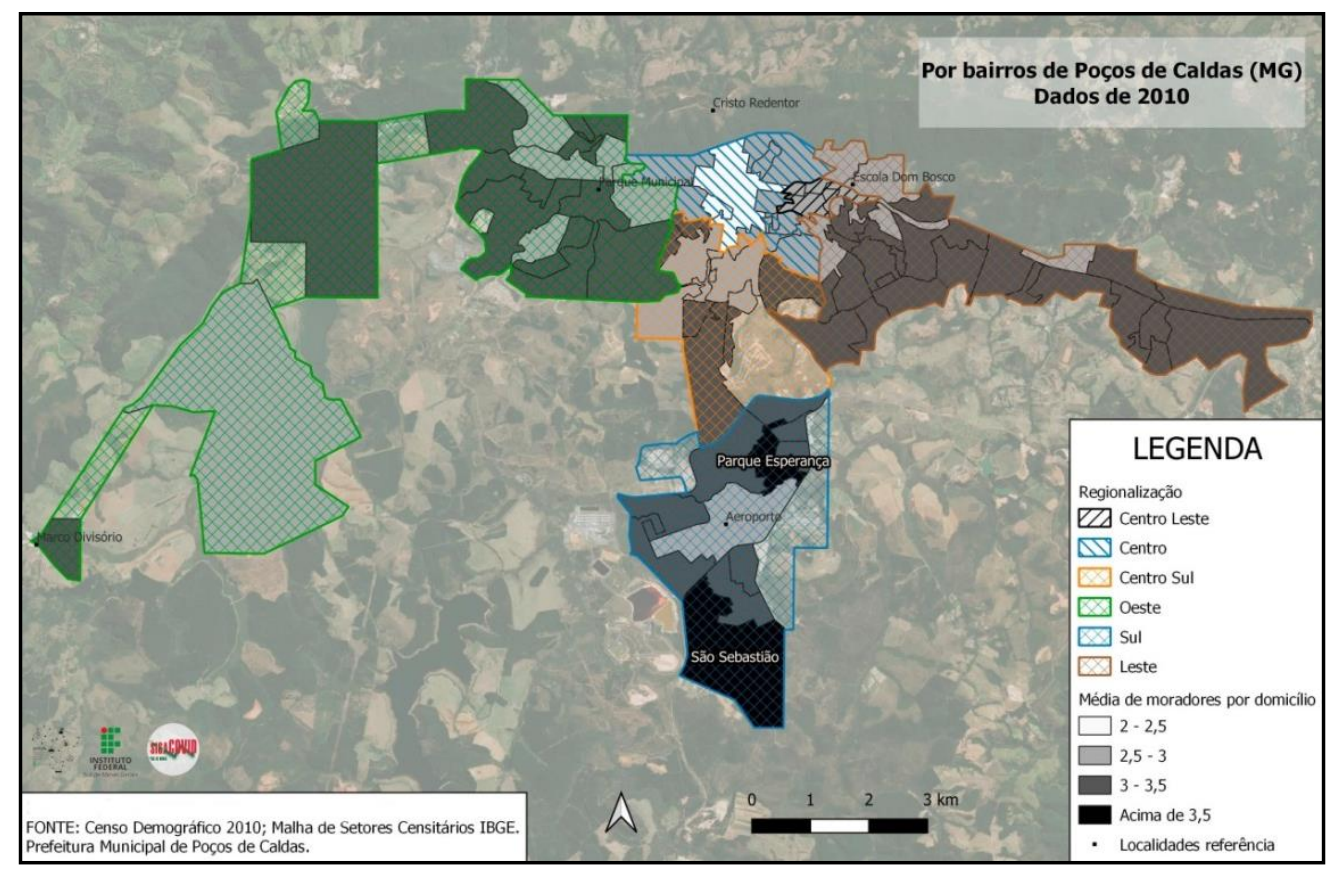

Fonte: GEPLAN-IFSULDEMINAS (2020).

A Figura 3 evidencia que, os setores censitários que correspondem aos

bairros Parque São Sebastião I e II, e Jardim Esperança I e II são os que apresentam maiores índices de densidade populacional por domicílio (acima de 3,5 moradores por domicílio). Os demais bairros da região Sul apresentam densidades de 2 a 3 moradores por domicílio.

Em grande maioria, os bairros da região Leste apresentam consideráveis índices de densidade populacional por domicílio (de 3 até 3,5 moradores por domicílio). Em contrapartida, o centro principal da cidade apresenta os menores índices de densidade populacional em seus setores censitários (de 2 até 2,5 moradores por domicílio). Isso se deve a diversos fatores, sendo: a função principal do centro é voltada às atividades de comércio e serviços, os aluguéis e compra dos imóveis no centro são, na maior parte dos casos, relativamente mais caros, se comparado aos aluguéis de outras regiões urbanas. 
Como já mencionado, a densidade populacional é um fator espacial que interfere na disseminação de epidemias. Ou seja, verifica-se que a densidade populacional por domicílio nos bairros das regiões Sul e nos bairros Leste são relativamente maiores, e isso se apresenta como um risco.

O mapa de Renda Média Mensal de Poços de Caldas (Figura 4) apresenta os rendimentos médios diferenciados dos bairros e regiões urbanas da cidade.

Figura 4 - Renda nominal média mensal

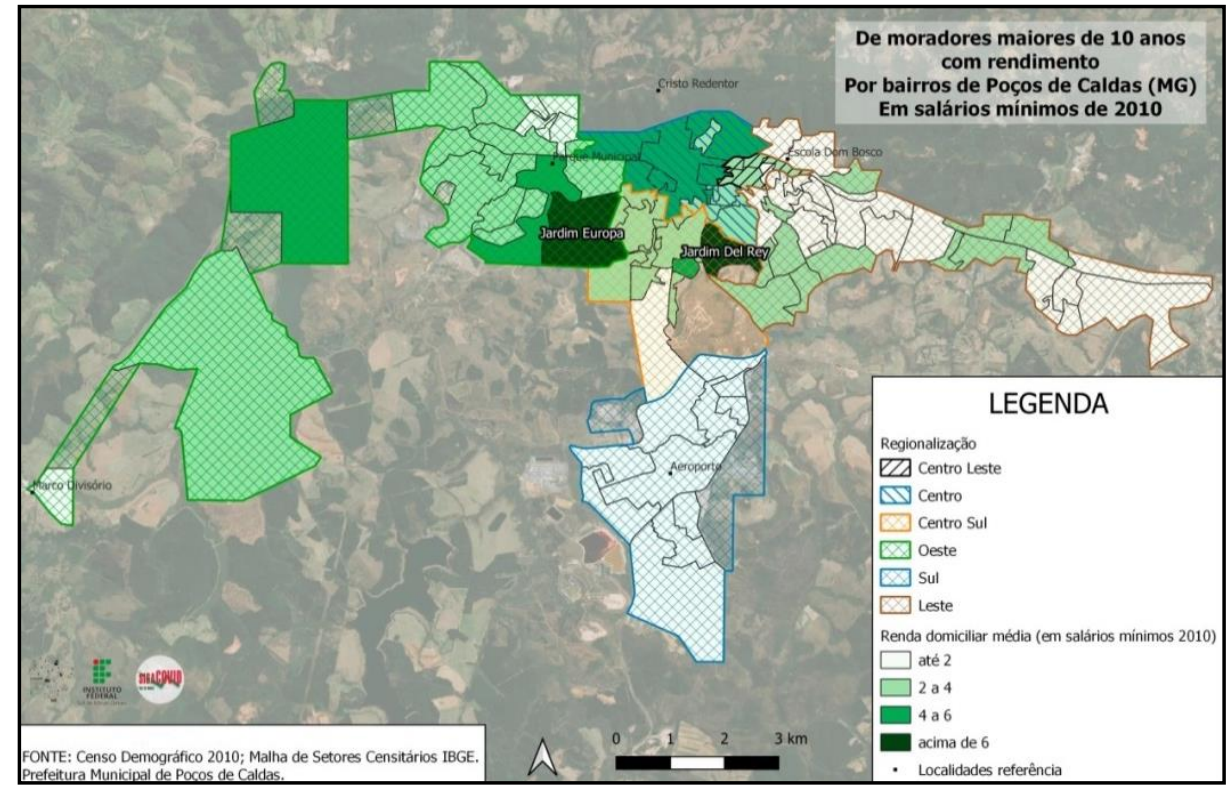

Fonte: GEPLAN-IFSULDEMINAS (2020).

As populações de baixa renda, que muitas vezes não têm condições de adquirir um veículo particular, se expõem ao alto risco de contágio quando dependem dos transportes coletivos, sobretudo quando estes apresentam superlotação. Outro ponto importante é que a população de baixa renda depende diretamente de seus trabalhos assalariados ou de trabalhos informais, sendo assim, o isolamento "voluntário" não é uma opção viável.

Percebe-se que, os bairros com maiores densidades de moradores por domicílio são também aqueles que apresentam menores rendimentos médios. A 
região Sul, como um todo, apresenta o menor índice (até 2 salários-mínimos). Também, os bairros mais afastados da região Leste apresentam o mesmo índice. Por sua vez, a Figura 5 revela que os maiores percentuais de pessoas pardas e negras se encontram nas regiões Sul e Leste, com 38\% e 29\%, respectivamente. Na região Sul, os bairros são compostos por populações que variam seus percentuais de população negra entre $20 \%$ e $50 \%$. Nessa região, os bairros que apresentaram entre $35 \%$ e $50 \%$ são aqueles que apresentaram maiores densidades de moradores por domicílio, como o Conjunto Habitacional Dr. Pedro Affonso Junqueira, Parque São Sebastião e o Jardim Esperança. A segunda região urbana com maiores percentuais de população parda e negra é a Leste (GEPLANIFSULDEMINAS, 2020).

Figura 5 - Percentual da população autodeclarada parda e negra, por regiões

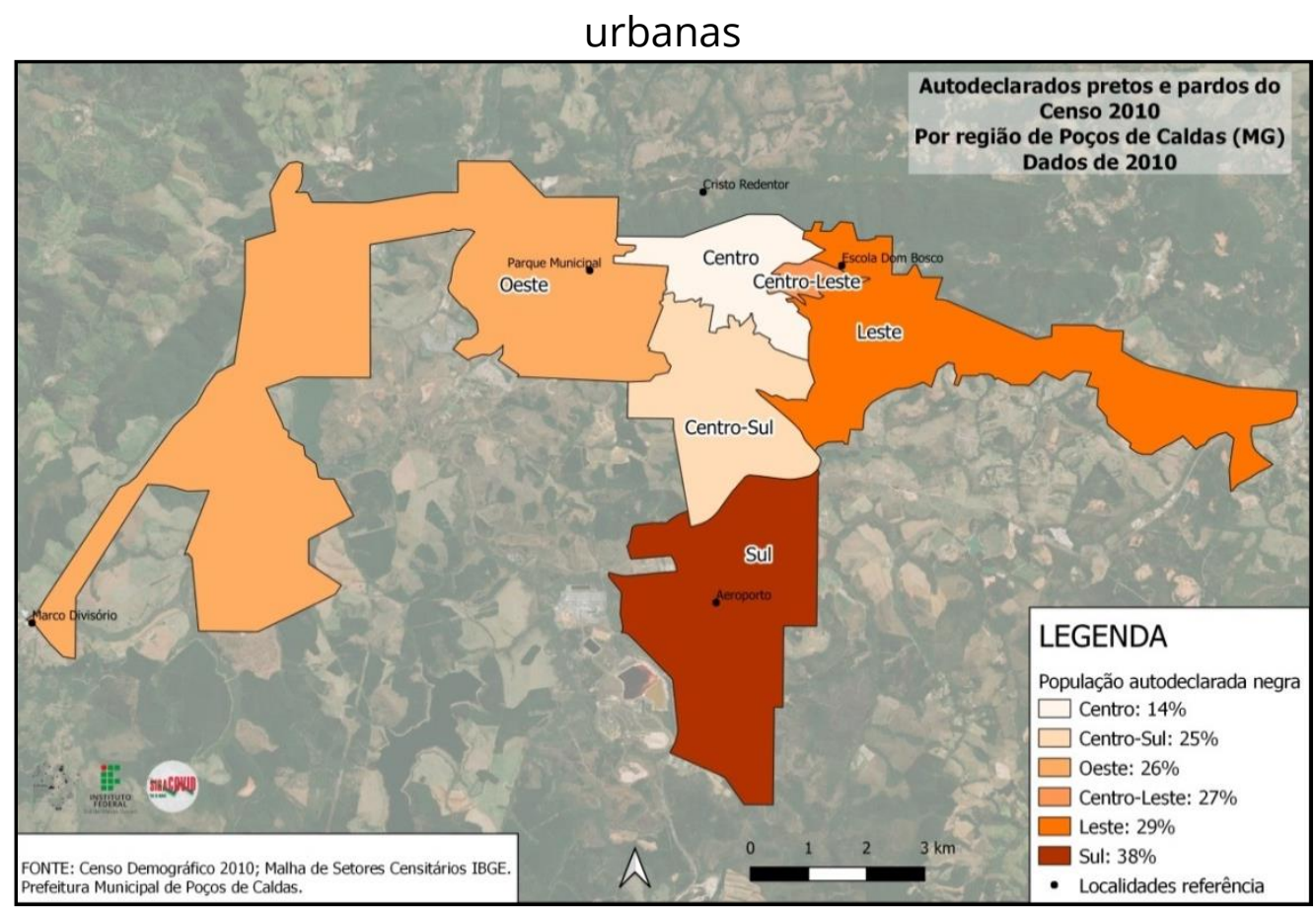

Fonte: GEPLAN-IFSULDEMINAS (2020).

\section{CONSIDERAÇÕES FINAIS}


Em Poços de Caldas, igualmente a qualquer outra cidade contemporânea inserida no sistema capitalista, há consideráveis desigualdades socioespaciais. As regiões urbanas Sul e Leste apresentam menores rendas médias dos moradores, maiores percentuais de população autodeclarada parda e negra, maiores médias de moradores por domicílio e maiores contingentes populacionais, se comparadas às outras regiões urbanas do município (GEPLAN-IFSULDEMINAS, 2020).

A maioria dos programas de habitação de interesse social foram implantados nas regiões Leste e Sul, o que reflete nos índices socioeconômicos, nos elevados contingentes populacionais e nas densidades demográficas de ambas. Essas regiões, que são mais periféricas socioeconômica e geograficamente, sofrem com o processo de segregação socioespacial (SILVA, 2021). Até o dia 8 de outubro de 2021, as regiões Leste e Sul apresentaram os maiores números de casos de COVID-19, sendo 5.327 (37\%) e 2.768 (19,23\%), respectivamente.

Considera-se que, de modo geral, as populações periféricas de baixa renda, que dependem de deslocamentos diários de transporte coletivo e que não puderam fazer um isolamento social efetivo, foram notavelmente afetadas pelo vírus durante a pandemia. Essa situação se agrava quando há falta de infraestrutura básica e de serviços básicos urbanos nas áreas urbanas das populações de menores rendimentos.

Em linhas gerais, muito ainda pode ser estudado sobre as dinâmicas e os impactos da propagação da COVID-19 sobre o espaço geográfico, visto que esta temática está longe de se esgotar. Ela é de elevada importância, pois garante bases científicas aos gestores locais, que poderão tomar decisões mais ágeis em seus territórios.

\section{AGRADECIMENTOS}


Ao Grupo de Estudos em Planejamento Territorial e Ambiental - GEPLAN IFSULDEMINAS; Ao coordenador do GEPLAN - IFSULDEMINAS, Prof. Dr. Sérgio Henrique de Oliveira Teixeira; Ao Programa de Pós-Graduação em Geografia PPGEO - da Universidade Federal de Alfenas.

\section{REFERÊNCIAS BIBLIOGRÁFICAS}

BARBOSA, J. L; TEIXEIRA, L. Territórios populares entre as desigualdades profundas e o direito à vida. In: CARLOS, Ana Fani Alessandri (Org.). COVID-19 e a crise urbana. São Paulo: FFLCH/USP, 2020. p. 67-77. Disponível em: < http://www.livrosabertos.sibi.usp.br/portaldelivrosUSP/catalog/view/471/423/16 4813>. Acesso em: 8 dez. 2020.

GEPLAN-IFSULDEMINAS. Análise da Distribuição e Difusão da COVID-19 na Mesorregião Sul/Sudoeste de Minas Gerais. Análise dos dados da COVID-19 no Município de Poços de Caldas/MG. Poços de Caldas: GEPLAN-IFSULDEMINAS, 2020. Relatório. 27 p. Disponível em: <https://geplan.org/2020/07/pesquisa-dogeplan-analisa-dados-sociais-e-economicos-para-mostrar-o-avanco-da-covid-19em-pocos-de-caldas/>. Acesso em: 2 set. 2020.

HARVEY, D. Política anticapitalista em tempos de COVID-19. Trad. SUELTO, L. In: DAVIS, M. et al (org.). Coronavírus e a luta de classes. Terra sem Amos: Brasil, 2020. p. 13-23.

Disponível em:

https://terrasemamos.files.wordpress.com/2020/03/coronavc3adrus-e-a-luta-declasses-tsa.pdf>. Acesso em: 13 jul. 2020.

INSTITUTO BRASILEIRO DE GEOGRAFIA E ESTATÍSTICA. Censo Demográfico de 2010. em: <https://www.ibge.gov.br/estatisticas/sociais/populacao/9662-censodemografico-2010.html?=\&t=o-que-e>. Acesso em: 10 mar. 2020.

INSTITUTO BRASILEIRO DE GEOGRAFIA E ESTATÍ́STICA. Poços de Caldas. Disponível em: < https://www.ibge.gov.br/cidades-e-estados/mg/pocos-de-caldas.html>. Acesso em: 1 out. 2021.

MARTINUCI, O. da S; FONZAR, U. J. V; BIATTO, J. F. P; FRANCISCO, I. C; AUGUSTO, I. J; GAZOLA, B. D. Análise geográfica da COVID-19 em Maringá/PR. Hygeia-Revista 
Brasileira de Geografia Médica e da Saúde, 2020, p. 88-101. Disponível em: <http://dx.doi.org/10.14393/Hygeia0054628>. Acesso em: 30 out. 2020.

MATSUMOTO, Patricia S. S; CREPALDI, M. T; AVANZI JÚNIOR, P. S; OLIVEIRA, M. B; REGALA, R. M. de S; ROSSEAL, T. V; LIMA, J. P. P. C. Mapeamento de covid-19 e isolamento social: ferramentas de monitoramento e vigilância em saúde pública. Hygeia-Revista Brasileira de Geografia Médica e da Saúde, 2020, p. 298-311. Disponível em: < http://dx.doi.org/10.14393/Hygeia0054553 >. Acesso em: 24 fev. 2021.

MBEMBE, A. Pandemia democratizou o poder de matar, diz autor da teoria da necropolítica. Folha de São Paulo, São Paulo, 30 mar. 2020. Mundo, p. 1-2. Disponível em: <https://www1.folha.uol.com.br/mundo/2020/03/pandemiademocratizou-poder-de-matar-diz-autor-da-teoria-da-necropolitica.shtml>. Acesso em: 8 dez. 2020.

OLIVEIRA, S. B. Impactos da Covid-19 nas periferias. 26 jun 2020. Disponível em: $<$ https://diplomatique.org.br/impactos-da-covid-19-nas-periferias/>. Acesso em: 9 ago. 2020.

PREFEITURA MUNICIPAL DE POÇOS DE CALDAS. Decreto $N^{\circ} 13.279$, do dia 18 de março de 2020. Estabelece medidas de prevenção e enfrentamento em face da Possibilidade de surto de doença infecciosa viral respiratória através do Coronavírus (COVID-19). Disponível em: <https://pocosdecaldas.mg.gov.br/> Acesso em: 21 ago. 2020.

PREFEITURA MUNICIPAL DE POÇOS DE CALDAS. Painel Coronavírus. Disponível em: <https://pocosdecaldas.mg.gov.br/covid-19/>. Acesso em: 10 out. 2021.

RIZZATTI, M; SPODE, P. L. C.; BATISTA, N. L.; ERTHAL, D. B; FARIA, R. M. de. Evolução e periferização da COVID-19 na área urbana de Santa Maria, RS: traçando padrões espaciais. Hygeia-Revista Brasileira de Geografia Médica e da Saúde, p. 441-449, 2020. Disponível em: <http://dx.doi.org/10.14393/Hygeia0054554>. Acesso em: 20 nov. 2020.

SILVA, E. de A. da. (Re)produção do espaço urbano e segregação socioespacial em Poços de Caldas, Minas Gerais. 2021. Dissertação (Mestrado em Geografia). Universidade Federal de Alfenas, Alfenas, MG, 2021. 211 f. Disponível em: < https://bdtd.unifal-mg.edu.br:8443/handle/tede/1832>. Acesso em: 1 jul. 2021.

VOLOCHKO, D. O cotidiano dos pobres não pode parar: a pandemia e a necrodemografia do capital. In: CARLOS, Ana Fani Alessandri (Org.). COVID-19 e a 
crise urbana. São Paulo: FFLCH/USP, 2020. p. 35-41. Disponível em: < http://www.livrosabertos.sibi.usp.br/portaldelivrosUSP/catalog/view/471/423/16 4813>. Acesso em: 8 dez. 2020.

VELAVAN, T. P.; MEYER, C. G. The COVID-19 epidemic. Tropical medicine \& international health, v. 25, n. 3, p. 278-280, 2020. Disponível em: <https://onlinelibrary.wiley.com/doi/10.1111/tmi.13383>. Acesso em: 20 nov. 2020. 